RESEARCH

\title{
EVALUATION OF PATIENTS FOLLOWED IN A PALLIATIVE CARE UNIT IN TURKEY
}

Turkish Journal of Geriatrics

DOI: 10.31086/tigeri.2021.219

2021; 24(2): 227-234

- Dursun ÇADIRCI ${ }^{1}$

- Yeşim AYAZÖZ2

- Şenay KOÇAKOĞLU1

CORRESPONDANCE

${ }^{1}$ Dursun ÇADIRCI

Harran University Faculty of Medicine,

Department of Family Medicine, Sanliurfa, Turkey

\section{Phone: +905054850090 \\ e-mail: drdcadirci@harran.edu.tr}

Received: Feb 25, 2021

Accepted: May 21, 2021

${ }^{1}$ Harran University Faculty of Medicine, Department of Family Medicine, Sanliurfa, Turkey

2 Oğuzeli Country State Hospital, Department of Family Medicine, Gaziantep, Turkey

\section{Abstract}

Introduction: The need for palliative care services is increasing day by day, but we think that these services are not sufficiently recognized by the society and health professionals. In this study, by presenting sociodemographic and clinical characteristics of the patients hospitalized in the palliative care unit together, we seek to raise awareness of palliative care services, which are still developing in Turkey.

Materials and Method: In this descriptive and retrospective study, 316 patients hospitalized in Palliative Care Unit of Harran University Research and Practice Hospital between April 2017- February 2019 were included. Sociodemographic characteristics and clinical data of the patients were evaluated. Falling risk is evaluated according to the Itaki Fall Risk Scale, Pressure Ulcers according to the guidelines published jointly by the National and European Pressure Ulcer Advisory Panels. The data were analyzed using frequency and percentage tests.

Results: Of 316 patients, $54.43 \%(n=172)$ were female, $45.57 \%(n=144)$ male; mean age was $66.23 \pm 19.66$ years (18-111). The most common reason for hospitalization was cerebrovascular disease with a rate of $22.15 \%(n=70)$, then respectively malignancy was at $20.89 \%(n=66)$, cardiovascular disease at $15.19 \%(n=48)$, asthma/chronic obstructive pulmonary disease and Alzheimer's disease at $5.70 \%(n=18)$. Comorbidity was found at $88.61 \%(n=280)$ and majority of the patients (67.72\%) were fed orally. The rate of patients with tracheostomy was $3.80 \%(n=12)$ and pressure ulcer at $23.70 \%(n=75)$.

Conclusion: Symptoms, pressure ulcers and nutritional support treatments in patients hospitalized in palliative care unit were presented with sociodemographic data. We believe that this study can help contribute to the awareness of palliative care and service scope, which is still developing in Turkey and around the world.

Keywords: Palliative Care; Pressure Ulcer; Nutritional Support; Aged. 


\section{INTRODUCTION}

Palliative care is a multidisciplinary approach that focuses on preventing and alleviating pain and promoting the best possible quality of life through early diagnosis, evaluation, and treatment of physical, mental, psychological and social problems of patients facing a terminal disease and those patient's families. It aims to relieve distress in all stages of the disease. Palliative care can be given at the same time with curative or life-extending treatments (1, 2). Palliative care is a set of services from birth to death that also includes the management of the family's mourning process after a patient's death (3).

The need for palliative care is increasing due to aging populations in Turkey and around the world (4). Cancers, central and peripheral neuronal diseases, muscle diseases, organ failures, irreversible trauma damages, infectious diseases such as HIV/ AIDS, progressive genetic congenital diseases in children can be counted among the diseases followed in palliative care (5). One of the basic principles of palliative care is symptom management. Common symptoms include pain, fatigue, anorexia, constipation, dyspnea, cough, nausea, diarrhea, and anxiety (6). In a systematic review, it was stated that early integration of palliative care enables better symptom management, longer survival and better quality of life (7). According to the World Health Organization (WHO), 40 million people need palliative care every year, and $78 \%$ of these people live in low- and middle-income countries (2). Palliative care should be developed at the primary care level, including home and community-based care. Providing palliative care should be seen as an ethical duty for healthcare professionals $(2,8)$.

The need for palliative care services is increasing day by day, but we think that these services are not sufficiently recognized by the society and health professionals. In this study, in which we evaluated data from a palliative care unit (PCU), we seek to increase the awareness about palliative care services that are still developing in Turkey by sharing nearly two years of experience.

\section{MATERIALS AND METHOD}

This retrospective study was carried out by examining the data of patients hospitalized in the PCU at Harran University Research and Application Hospital in Sanliurfa, a city of over two million residents in southeastern Turkey. The study universe consisted of 316 patients hospitalized in that PCU between April 2017 and February 2019. For patients with repeated hospitalizations, data from first hospitalizations were evaluated. This study was undertaken with the approval of the Ethics Committee of Harran University Medical Faculty.

Patient data such as sociodemographic characteristics, general conditions, duration of hospital stay, activity status, falling risks, comorbidities, feeding patterns, pressure ulcers, tracheostomy status, reasons for receiving caregiver support, and status upon leaving PCU were evaluated. The falling risks of the patients were evaluated according to the Itaki Fall Risk Scale scores developed by the Ministry of Health, which was developed specifically for our country to prevent patients from falling (9). The results obtained by evaluating the patients with the Fall Risk Scale were divided into two groups; if the total score is below 5, it is considered as low risk and if the total score is above 5 , it is considered as high risk. For pressure ulcer staging, the stages published by the European Pressure Ulcer Advisory Panel (EPUAP) and the National Pressure Ulcer Advisory Panel (NPUAP) were used (10).

The data were analyzed using the IBM Statistical Package for the Social Sciences version 20 (SPSS Inc., Chicago, IL, USA). Descriptive analytical methods (means for continuous variables and percentages for categorical variables) were used in evaluating the data. The results were evaluated at a 95\% confidence interval, and the significance level was $\mathrm{p}<0.05$.

Ethical approval was obtained from the local Ethics Committee (approval number: HRÜ/19.03.3711.03.2019-03) 


\section{RESULTS}

Of the 316 patients hospitalized in the PCU and included in the study, $54.43 \%(n=172)$ were female and $45.57 \%(n=144)$ male; the mean age was $66.23 \pm 19.66$ (18-111). From a demographic perspective, 66.54\% ( $n=171)$ were married, 53.48\% ( $n=169)$ lived in the city, and $44.30 \%(n=140)$ were illiterate. The complete sociodemographic characteristics of the patients included in the study are presented in Table 1.

It was found that $62.00 \%$ of the patients' $(n=196)$ general status was moderate, and $50 \%(n=158)$ were dependent when their activity status was examined. Fall risk scores placed $76.58 \%(n=242)$ of patients in the high-risk, the average fall risk score was $10.62 \pm 6.87(0-40)$. When feeding status was examined, $67.72 \%(n=214)$ of patients were fed orally. $3.80 \%(n=12)$ of the patients had tracheostomy.
Pressure ulcers were present in $23.70 \%(n=75)$ of patients and the majority of them were stage- 2 ulcers in $40.00 \%(n=30)$. More detailed information about the patients' health characteristics is presented in Table 2.

The most common reason for hospitalization was cerebrovascular disease. Other most common reasons for hospitalization were malignancy at $20.89 \%(n=66)$, cardiovascular disease at $15.19 \%$ $(n=48)$, asthma/ chronic obstructive pulmonary disease (COPD) at $5.70 \%(n=18)$, Alzheimer's disease at $\% 5.70(n=18)$. The detailed information on reasons for hospitalization is presented in Table 3.

Comorbidity was found in $88.61 \%$ of the patients $(n=280)$, involving diseases such as hypertension, diabetes mellitus, cardiovascular disease, asthma, COPD, hepatitis, cerebrovascular disease, cancer, Alzheimer's, and Parkinson's. The most common

Table 1. Sociodemographic characteristics of the patients

\begin{tabular}{|c|c|c|}
\hline & \multicolumn{2}{|c|}{ Mean \pm SD (Min- Max) } \\
\hline \multirow[t]{2}{*}{ Age (year) } & \multicolumn{2}{|c|}{$66.23 \pm 19.66(18-111)$} \\
\hline & & n (\%) \\
\hline Gender & $\begin{array}{l}\text { Female } \\
\text { Male }\end{array}$ & $\begin{array}{l}172(54.43) \\
144(45.57)\end{array}$ \\
\hline Marital status & $\begin{array}{l}\text { Single } \\
\text { Married } \\
\text { Widow } \\
\text { Unknown }\end{array}$ & $\begin{array}{l}22(8.56) \\
171(66.54) \\
64(24.90) \\
59(18.70)\end{array}$ \\
\hline Working status & $\begin{array}{l}\text { Not working } \\
\text { Working } \\
\text { Unknowna }\end{array}$ & $\begin{array}{l}233(73.73) \\
51(16.14) \\
32(10.13)\end{array}$ \\
\hline Residential area & $\begin{array}{l}\text { Rural } \\
\text { Town } \\
\text { Urban } \\
\text { Unknown }\end{array}$ & $\begin{array}{c}35(11.08) \\
23(7.28) \\
169(53.48) \\
89(28.16)\end{array}$ \\
\hline Education status & $\begin{array}{l}\text { Illiterate } \\
\text { Literate/ Primary education } \\
\text { High school/ University } \\
\text { Unknown }\end{array}$ & $\begin{array}{l}140(44.30) \\
91(28.79) \\
12(3.79) \\
73(23.12)\end{array}$ \\
\hline
\end{tabular}

a Refers to those whose information cannot be reached from the files 
Table 2. Clinical features of the patients

\begin{tabular}{|l|l|c|}
\hline & & $n(\%)$ \\
\hline General status & Good & $24(7.60)$ \\
& Middle & $196(62.00)$ \\
& Bad & $67(21.20)$ \\
& Unknown & $29(9.20)$ \\
\hline Activity status & Dependent & $158(50.00)$ \\
& Semi dependent & $106(33.54)$ \\
& Independent & $52(16.46)$ \\
\hline Falling risk & Low risk & $74(23.42)$ \\
& High risk & $242(76.58)$ \\
\hline Comorbid disease & Yes & $280(88.61)$ \\
& No & $36(11.39)$ \\
\hline Feeding style & Oral & $214(67.72)$ \\
& Nasogastric & $41(12.97)$ \\
& Percutaneous endoscopic gastrostomy & $23(7.28)$ \\
& Parenteral & $38(12.03)$ \\
\hline Tracheostomy & Yes & $12(3.80)$ \\
& No & $304(96.20)$ \\
\hline Pressure ulcer & Yes & $75(23.70)$ \\
& No & $241(76.30)$ \\
\hline Stage of the pressure ulcer & Stage-1 & $9(12.00)$ \\
& Stage-2 & $30(40.00)$ \\
& Stage-3 & $19(25.33)$ \\
& Stage-4 & $17(22.67)$ \\
\hline
\end{tabular}

${ }^{a}$ Refers to those whose information cannot be reached from the files.

complaints reported by patients or their relatives were malnutrition with a rate of $38.30 \%(n=167)$, pressure ulcer $20.41 \%(n=89)$, cough or respiratory distress $14.45 \%(n=63)$, weakness or fatigue $9.40 \%$ $(n=41)$, nausea or vomiting $4.13 \%(n=18)$, abdominal pain $4.13 \%(n=18)$, urinary tract problems $3.21 \%$ $(n=14)$, dizziness or headache $2.52 \%(n=11)$, syncope or convulsions $2.29 \%(n=10)$, and fever $1.15 \%$ $(n=5)$. In some patients, there was more than one complaint at the time of application.

All patients had caregiver support; $53.48 \%$ $(n=169)$ of caregivers were spouses, $8.23 \%(n=26)$ fathers, $1.58 \%(n=5)$ mothers, $1.90 \%(n=6)$ brides, $12.34 \%(n=39)$ daughters, $3.16 \%(n=10)$ sons, and
$3.80 \%(n=12)$ other relatives. Information about caregivers was not available for $15.51 \%(n=49)$ patients.

It was observed that $62.34 \%(n=197)$ of patients were transferred from another service, $23.42 \%(n=74)$ from the emergency service, and $14.24 \%(n=45)$ from the polyclinic. The mean duration of hospitalization of patients in the PCU was $13.92 \pm 20.35$ days (1-250). According to the analysis of the patients' manner of leaving the PCU, 63.92\% ( $n=202)$ were discharged, $18.35 \%(n=58)$ were referred to the intensive care unit, and $13.92 \%(n=44)$ to other wards. $3.80 \%$ of the patients $(n=12)$ died in the PCU. 
Table 3. Reasons for hospitalization

\begin{tabular}{|l|c|}
\hline Diagnosis & $\mathrm{n}(\%)$ \\
\hline Cerebrovascular disease & $70(22.15)$ \\
\hline Malignancy & $66(20.89)$ \\
\hline Cardiovascular disease & $48(15.19)$ \\
\hline Asthma / COPD & $18(5.70)$ \\
\hline Alzheimer's & $18(5.70)$ \\
\hline Paraplegia / tetraplegia & $16(5.06)$ \\
\hline Diabetes and its complications & $13(4.11)$ \\
\hline Trauma & $10(3.16)$ \\
\hline Pulmonary thromboembolism & $9(2.85)$ \\
\hline Parkinson's & $7(2.22)$ \\
\hline Psychiatric illness & $7(2.22)$ \\
\hline Pre / post-op & $7(2.22)$ \\
\hline Others & $27(8.53)$ \\
\hline
\end{tabular}

\section{DISCUSSION}

Medical and technological developments observed worldwide have brought about many improvements in living conditions. Thus, the life span has been extended, and survival times for chronic and deadly diseases have increased. Palliative care, which has been developing rapidly in recent years in Turkey, is a care system aimed at increasing the quality of life in progressive, incurable, and fatal diseases. Palliative care is a multidisciplinary practice that requires the coordinated work of different clinical specialties and professional groups. It is an important service step for physicians and for patients and their relatives (11). In this study, there was a heterogeneous patient population with a predominantly female population, including young patients. Cerebrovascular diseases were the leading cause of patients' need for palliative care and pressure ulcer rates were low.

In a study conducted by Dinçer et al. with patients hospitalized at a palliative care in Turkey, $54.1 \%$ of 111 patients were male and $45.9 \%$ female. They reported a median duration for in-patient care of 24 days (range, 6-212) (12). In a study conducted by Yürüyen et al. with 319 patients hospitalized in a palliative care center, the mean age was $71 \pm 15.8$ years, and the mean hospitalization period was 15.4 \pm 15.7 days (13). Dinçer et al. followed 435 patients in a palliative care center; $58.60 \%$ of the participants were male, $41.40 \%$ were female, the mean age was $70.6 \pm 17.2$ years, and the duration of hospitalization was $27.2 \pm 30.9$ days (14). In a study by Komaç et al. that retrospectively examined the clinical files of 258 patients hospitalized in the PCU of an internal diseases' clinic, the mean age of patients was 61.4 years (19-93), and the average length of stay was 9.4 days (1-68) (15).

In a study conducted by Dinçer et al., 52.2\% of patients received nutritional support treatment; $40.5 \%$ had pressure ulcers, $42.3 \%$ neurological disease, $23.4 \%$ cancer, $41.4 \%$ chronic systemic conditions (diabetes mellitus and chronic pulmonary, cardiac, and renal disease), and 10.8\% infections (12). The most common comorbid diseases reported by Yürüyen et al. were malnutrition (59\%), malignancy $(44 \%)$, infectious disease (33\%), pressure ulcer (33\%), and cerebrovascular disease (9.7\%). The most common admissions complaints were oral intake disorder (35\%), general condition disorder (19\%), fever (17\%), anorexia and weight loss (15\%), and fatigue (13\%) (13). The most common complaints of patients or their relatives in the present study were malnutrition, pressure ulcer, cough or respiratory distress, weakness or fatigue, nausea or vomiting, abdominal pain, urinary tract problems, dizziness or headache, syncope or convulsion, and fever. In a study by Komaç et al., 33.30\% of patients were followed up for malignancy and complications related to malignancy, $17 \%$ for the completion of prolonged 
antibiotic treatment initiated for reasons such as pneumonia, urinary tract infection, pancreatitis, and $17 \%$ for complications due to diabetes (15). Palliative care focuses on symptom control regardless of the cause of the disease and should not be associated with purely terminal care. It provides additional support in patient care, especially with cancer (16). In the present study, the five most common reasons for hospitalization were cerebrovascular disease, malignancy, cardiovascular disease, asthma/COPD, and Alzheimer's and related complications.

It has been reported in the literature that the lifetime risk of stroke is approximately 25\% (17). In present study, the rate of hospitalization due to cerebrovascular disease was $22.15 \%$. Miniksar et al. reported that $12.77 \%$ of patients in their study had cerebrovascular disease (18), while Dinçer et al. reported a neurological disease rate of $42.3 \%$ (12). In present study, the majority of the patients suffered from serebrovascular disease. These palliative care patients can benefit from a structured approach to their needs and easing symptom burden. In addition, a holistic approach can improve their overall quality of life (19).

An evaluation of the mobilization status of patients in Yürüyen et al. showed that $75 \%$ were inactive, $15.30 \%$ semi-mobile, and $9.70 \%$ mobile (13). As to the activity status of the patients in the present study, the percentage of dependent patients is lower, but the proportions of semi-dependent and independent patients are higher. Studies have shown that immobility is an important risk factor in the development of pressure ulcers (20-22).

Yürüyen et al. observed that $71.90 \%$ of the patients were fed enterally and $28.10 \%$ parenterally. Of patients fed enterally, $75.90 \%$ were fed orally, $11.80 \%$ with nasogastric tube, and $12.20 \%$ with percutaneous endoscopic gastrostomy. Pressure ulcers were present in $33.50 \%$ of the patients; stage-2 pressure ulcers were most commonly seen (13). Similar to Yürüyen et al., most of the patients in present study were fed orally and the majority of those with pressure ulcers were also stage-2, but pressure ulcer rates were lower.

Dinçer et al. reported that $46.20 \%$ of the patients they followed up in the palliative care center lost their lives (14). In Yürüyen et al., 52\% of patients were discharged, $15.30 \%$ were transferred to advanced intensive care, and $33.60 \%$ died (13). Roldi et al. reported that $6 \%$ of patients died, while $92.3 \%$ were discharged (23). The mortality rate in Sargın et al. was reported as $21.5 \%$ (24). In the present study, $3.80 \%$ of the patients lost their lives in the PCU.

Most of the patients hospitalized in the PCU were elderly patients with comorbidities whose general health status ranged from moderate to poor. Evaluation of their activity status showed that more than half of patients were dependent and at high risk of falling. Nutrition support, wound care, pain palliation, and rehabilitation services were planned for these patients; they were treated for their infectious and chronic diseases.

\section{CONCLUSION}

Palliative care includes multidisciplinary practices that require strong coordination and cooperation. In this study, in which we shared clinical experiences with PCU, it was seen that majority of patients were elderly dependent individuals who needed support in matters such as nutrition and wound care due to problems such as cerebrovascular disease and malignancy. Palliative care services are handled within the scope of human rights and it is suggested to be developed and expanded also at the level of primary health care services. We believe that this study will increase the awareness about palliative care services which still developing in Turkey and around the world. Sharing the data of palliative care services across the country will be an important step.

Conflict of interest: The authors declare no conflicts of interest. 


\section{REFERENCES}

1. Sepúlveda C, Marlin A, Yoshida T, Ullrich A. Palliative care: the World Health Organization's global perspective. J Pain Symptom Manage 2002;24(2):91-6. (PMID: 12231124).

2. World Health Organization WHO. Palliative Care 2020 [Internet]. Available from: https://www.who.int/ news-room/fact-sheets/detail/palliative-care. Accessed: 09.01.2020.

3. Saunders C. The Depths and the Possible Heights. Med News 1964;10:16-17. (DOI:10.1093/acprof:oso/9780198570530.003.0012).

4. Tekin N. An Example of Support Program to Elderly Patient and Elderly Relative During the Terminal Period in a Developed Model of Residential Home and Geriatric Care Center. Turkish Journal of Geriatrics 2011;14(3):273-5. (in Turkish).

5. Kabalak AA. Palliative Care Patient, Palliative Care Admission and Discharge Criteria. In: Kabalak AA (Eds). Palliative Care Guide. Dünya Tıp Kitabevi, Ankara, 2018, pp. 17-9.

6. Kivanç MM. Palliative Care Services in Turkey. HSP. 2017;4 (2):132-5. (in Turkish) (DOI: 10.17681/hsp-dergisi.316894).

7. Dalgaard KM, Bergenholtz $H$, Nielsen ME, Timm H. Early integration of palliative care in hospitals: A systematic review on methods, barriers, and outcome. Palliat Support Care. 2014 Dec;12(6):495-513. doi: 10.1017/S1478951513001338. Epub 2014 Mar 13. PMID: 24621947.

8. Al-Mahrezi A, Al-Mandhari Z. Palliative Care: Time for Action. Oman Med J. 2016 May;31(3):161-3. doi: 10.5001/omj.2016.32. PMID: 27162584; PMCID: PMC4852088.

9. Özlü ZK, Yayla A, Özer N, Gümüş K, Erdağı S, Kaya Z. Risks of Falling in Surgical Patients. Kafkas J Med. 2014;5(3):94-9. (in Turkish) (DOI:10.5505/ kjms.2015.19870).

10. European Pressure Ulcer Advisory Panel and National Pressure Ulcer Advisory Panel. Prevention and treatment of pressure ulcers: quick reference guide. Washington DC: National Pressure Ulcer Advisory Panel; 2009.
11. Egici MT, Can MK, Toprak D et al. Care Burden and Burnout Status of Caregivers Whose Patients are Treated in Palliative Care Centers. JAREN. 2019;5(1):18. (in Turkish) (DOI:10.5222/jaren.2019.38247).

12. Dincer $M$, Kahveci K, Döğer C, Gökçinar D, Yarici Ak, Taş H. Factors Affecting the Duration of Admission and Discharge in a Palliative Care Center for Geriatric Patients. Turkish Journal of Geriatrics. 2016;19(2):74-80.

13. Yürüyen M, Tevetoğlu IÖ, Tekmen Y, Polat Ö, Arslan İ, Okuturlar Y. Prognostic Factors and Clinical Features in Palliative Care Patients. Konuralp Medical Journal. 2018;10 (1):74-80. (in Turkish) (DOI: 10.18521/ ktd.368570).

14. Dincer M, Kahveci K, Doger C. An Examination of Factors Affecting the Length of Stay in a Palliative Care Center. J Palliat Med 2018;21(1):11-5. ( PMID: 28622477).

15. Komaç A, Elyiğit F, Türemiş C, Gram E, Akar H. Retrospective Analysis of Hospitalized Patients in Tepecik Training and Research Hospital Internal Medicine Palliative Care Unit. FNG \& Science Medical Journal. 2016;2 (1):1-3. (in Turkish) (DOI: 10.5606/fng. btd.2016.001).

16. Alexander K, Goldberg J, Korc-Grodzicki B. Palliative Care and Symptom Management in Older Patients with Cancer. Clin Geriatr Med. 2016;32(1):4562. (PMID: 26614860).

17. Global Burden of Disease Stroke Expert Group. Global, Regional, and Country-Specific Lifetime Risks of Stroke, 1990 and 2016. N Engl J Med. 2018;379(25):2429-37. (PMID: 30575491).

18. Miniksar ÖH, Aydin A. Retrospective Analysis of Hospitalized Patients in Our Palliative Care Unit. J Contemp Med 2019;10 (3):1-5. (in Turkish) (DOI: 10.16899/jcm.624878).

19. Steigleder T, Kollmar R, Ostgathe C. Palliative Care for Stroke Patients and Their Families: Barriers for Implementation. Front Neurol 2019;10(164):1-8. (PMID: 30894836).

20. Langemo DK, Black J. Pressure Ulcers in Individuals Receiving Palliative Care: A National Pressure Ulcer Advisory Panel White Paper@. Adv Skin Wound 
Care. 2010;23(2):59-72.( PMID: 20087072).

21. Galvin J. An Audit of Pressure Ulcer Incidence in a Palliative Care Setting. Int J Palliat Nurs 2002;8(5):21421. (PMID: 12048504).

22. Dincer M, Doger C, Tas SS, Karakaya D. An Analysis of Patients in Palliative Care with Pressure Injuries. Niger J Clin Pract 2018;21(4): 484-91. (PMID: 29607862).
23. Roldi MdS, Moritz RD. Evaluation of the Symptoms and Treatment Prescribed to Hospitalized Patients. Rev Ass Med Brasil 2016;62(4):307-14. PMID: (27437674).

24. Sargin M, Demirel HF. Relationship Between Mortality and the Laboratory Values at Admission to Palliative Care Unit in Geriatric Patients with No Diagnosis of Malignancy. Turkish Journal of Geriatrics 2019;22(4):434-42. (DOI: 10.31086/tjgeri.2020.122). 